\title{
PENERAPAN RETORIKA VISUAL PADA PERANCANGAN MEDIA KAMPANYE PRODUK MAKANAN OLEH-OLEH KHAS KABUPATEN BANDUNG WILAYAH SELATAN
}

\author{
Birgita Nindya Karina ${ }^{1}$, Monica Hartanti ${ }^{2}$ dan Irawati Tirtaatmadja ${ }^{3}$ \\ 1,2,3Universitas Kristen Maranatha
}

Received: 25 Januari 2018

Revised: 22 Maret 2018

Accepted: 25 Maret 2018

Available online at: bit.do/demandia

\begin{abstract}
Abstrak: Kabupaten Bandung Wilayah Selatan merupakan sentra dari hasil potensi alam yang ada di Kabupaten Bandung. Potensi alam tersebut dimanfaatkan sebagai daya tarik wisata dan juga hasil alamnya dapat diolah menjadi makanan khas setempat yang biasanya dijadikan oleh-oleh. Banyak penduduknya yang tergabung dalam Usaha Kecil Menengah (UKM) yang mengelola hasil alam tersebut menjadi makanan oleh-oleh seperti opak, dodol strawberry, bandrek, dan kalua jeruk. Namun disayangkan, banyak masyarakat yang belum mengenali produk makanan oleh-oleh khas Kabupaten Bandung wilayah Selatan ini, sehingga eksistensi dari produk makanan ini masih kurang. Perancangan ini menggabungkan metode analisis kualitatif dan kuantitatif. Metode kualitatif dalam bentuk observasi pada produk makanan oleh-oleh di daerah Kabupaten Bandung Selatan dan wawancara dengan narasumber perwakilan Seksi Industri Makanan dan Minuman di Dinas Perindustrian Kabupaten Bandung. Metode kuantitatif dalam bentuk penyebaran kuesioner kepada 100 responden menggali informasi terhadap pengetahuan responden tentang Kabupaten Bandung wilayah Selatan dan kuliner. Perancangan ini didukung juga dengan studi pustaka mengenai Retorika visual dan Leksia. Pemecahan masalah dalam perancangan ini adalah dengan melakukan perancangan kampanye yang ditujukan bagi remaja dan dewasa muda dengan gaya visual retorika Anthropomorpism dan Methapor. Produk makanan tersebut diumpamakan sebagai target market yang sedang berlibur di lokasi Bandung Selatan dengan aktivitas yang sedang trendi saat ini. Visualisasi tersebut diharapkan akan membangun citra visual pada produk makanan oleh-oleh khas Bandung Selatan sebagai produk makanan yang alami dan trendi. Tujuan akhir dari perancangan ini adalah agar produk makanan oleh-oleh khas Bandung selatan semakin dikenal oleh masyarakat luas.
\end{abstract}

Kata kunci: Bandung Selatan, Kampanye, Makanan oleh-oleh, Retorika visual

\begin{abstract}
South Bandung Regency is a center of natural potency in the Bandung Regency. It is utilized as a tourism attraction and its natural product can be produced to be typical local food that is usually made as gifts. Most of the people there joining the Small Medium Enterprises (SMEs) manufacture the natural sources become eatable gifts such as opak, dodol strawberry, bandrek, and kalua jeruk. Unfortunately, many people haven't appreciated this food product, a gift made in Bandung regency, hence its existence is
\end{abstract}

Birgita Nindya Karina ${ }^{1}$, Monica Hartanti ${ }^{2}$ dan Irawati Tirtaatmadja ${ }^{3}$ email: ${ }^{1}$ bnkarina@gmail.com, 2monica26hartanti@gmail.com 
fading. This study uses mixed methods, involving observation on the food product and interview the source, a representative of food and drink industry division at Bandung Industry Department. Quantitative method is conducted in distributing questionnaire to 100 participants to investigate their knowledge about South Bandung regency and the culinary. The research is also completed with literature study and visual and lexical rhetoric. The problem solution given is designing a campaign for teens and young adults with the rhetoric visual of Anthropomorphism and Metaphor. The food product is associated as target markets making a popular activities lately and enjoying vacation in South Bandung. The visualization is expected to build a visual image on those typical South Bandung gift as natural and popular food products. The purpose is to make it more familiar for public.

Keywords: Campaign, Food souvenirs, South Bandung, Visual Rhetoric

\section{PENDAHULUAN}

Bandung merupakan salah satu kota di Jawa Barat yang memiliki daya tarik wisata melalui kulinernya. Dibuktikan dengan ditetapkannya Kota Bandung sebagai destinasi wisata kuliner Indonesia oleh menteri pariwisata, Arief Yahya. Keberagaman citarasa kuliner tersebut dikarenakan kondisi geografis Bandung yang memiliki sumber daya alam yang melimpah, salah satunya adalah daerah Kabupaten Bandung wilayah Selatan yang mencakup Kecamatan Soreang, Margaasih, Katapang, Rancabali, Ciwidey, dan Pasir Jambu.

Berdasarkan observasi yang telah dilakukan, sebagian besar daerah Kabupaten Bandung Wilayah Selatan merupakan sentra dari hasil potensi alam sekitar, sehingga banyak penduduknya tergabung dalam Usaha Kecil Menengah (UKM) yang memanfaatkan hasil alam sekitar dan mengolahnya menjadi produk makanan oleh-oleh khas daerah Kabupaten Bandung Wilayah Selatan. Produk makanan oleh-oleh tersebut antara lain adalah opak dari Kecamatan Soreang, dodol stroberi dari Kecamatan Rancabali, bandrek dari Kecamatan Ciwidey, dan kalua jeruk dari Kecamatan Pasir Jambu. Resep turun temurun dari penduduk sekitar yang dibuat dengan menggunakan bahan dasar alami menciptakan rasa khas pada makanan oleh-oleh Kabupaten Bandung wilayah Selatan yang mana 
akan menjadi keunggulan produk. Hal tersebut diperkuat juga dengan hasil kuesioner yang menyatakan bahwa sebagian besar responden tertarik dengan produk makanan khas daerah yang memiliki cita rasa unik dan berbahan alami.

Sejauh ini upaya yang telah dilakukan oleh Dinas Perindustrian Kabupaten Bandung adalah memberikan "wadah" kepada produsen dalam bentuk acara pameran yang diadakan dalam waktu tertentu. Belum ada strategi kampanye khusus yang dilakukan untuk lebih memperkenalkan produk makanan oleh-oleh tersebut. Hal ini dibenarkan oleh Maya Kusuma Dewi (2017), selaku Kepala Seksi Industri Makanan dan Minuman di Dinas Perindustrian Kabupaten Bandung. Menurutnya, penjualan produk makanan khas Kabupaten Bandung Wilayah Selatan masih bisa dimaksimalkan apabila masyarakat lebih mengenal tentang ragam produk makanan khas yang diolah dari hasil alam yang ada di Kabupaten Bandung Wilayah Selatan.

Adanya latar belakang permasalahan yang telah dipaparkan di atas, perlu dilakukan upaya untuk memperkenalkan produk makanan oleh-oleh khas Bandung Selatan yang memiliki cita rasa unik dan berbahan alami melalui media kampanye.

\section{KAJIAN TEORI}

Adapun teori-teori relevan yang diterapkan dalam studi ini antara lain teori kampanye, teori retorika visual, teori leksia, efektifitas sosial media, teori warna Sunda. Kampanye pada prinsipnya merupakan suatu proses kegiatan komunikasi individu atau kelompok yang dilakukan secara terlembaga dan bertujuan untuk menciptakan suatu efek atau dampak tertentu. Menurut Rogers dan Storey (1987) dalam Venus (2004: 7) kampanye sebagai serangkaian tindakan komunikasi yang terencana dengan tujuan untuk menciptakan efek tertentu pada sejumlah besar khalayak yang dilakukan secara berkelanjutan pada kurun waktu tertentu. 
Menurut Larson (1992) dalam Venus (2004), terdapat tiga kategori jenis kampanye yakni:

\section{Product-oriented campaigns}

Istilah lain yang sering digunakan oleh kampanye jenis ini adalah commercial campaigns atau corporate campaign. Motivasi yang mendasarinya adalah memperoleh keuntungan finansial. Cara yang ditempuh adalah dengan memperkenalkan produk dan melipatgandakan penjualan sehingga diperoleh keuntungan yang diharapkan.

\section{Candidate-oriented campaigns}

Biasanya dimotivasi oleh hasrat untuk meraih kekuasaan politik. Karena itu jenis kampanye ini dapat juga disebut sebagai political campaigns (kampanye politik). Tujuannya jelas antara lain untuk memenangkan dukungan masyarakat terhadap kandidat-kandidat yang diajukan partai politik agar dapat menduduki jabatan-jabatan politik yang diperebutkan lewat proses pemilihan umum.

\section{Ideologically or cause oriented campaigns}

Jenis kampanye yang berorientasi pada tujuan-tujuan yang bersifat khusus dan sering kali berdimensi perubahan sosial. Karena itu kampanye jenis ini dalam istilah Kotler disebut sebagai social change campaigns, yaitu kampanye yang bertujuan untuk mengatasi masalah-masalah sosial melalui perubahan sikap dan perilaku publik yang terkait dengan topik masalah.

Pada studi ini, jenis kampanye yang digunakan yaitu Product-oriented campaigns dan Ideologically or cause oriented campaigns, karena tujuan dari kampanye ini untuk memperkenalkan produk makanan oleh-oleh khas Kabupaten Bandung Wilayah Selatan kepada masyarakat luas sehingga dapat meningkatkan 
penjualan produk serta menunjang kesejahteraan para produsen atau UKM yang telah mengelola produk-produk tersebut.

Diperlukan model kampanye sebagai upaya untuk memudahkan pemahaman tentang proses pengiriman dan penyampaian pesan kampanye kepada target market. Model kampanye yang dipilih dalam perancangan ini dari Leon Ostergaard dikenal dengan istilah "3A", yaitu Awareness, Attitude dan Action. Aspek Awarness- pengetahuan (knowledge), sikap (attitude) dan perilaku (action/behavioural).

Diawali dengan tahap Awareness untuk menarik perhatian dan menyadarkan masyarakat tentang adanya hal yang ingin dikampanyekan, kemudian dilanjutkan dengan tahap Attitude untuk memberikan informasi lebih detail tentang pesan komunikasi yang ingin disampaikan, sehingga akan menimbulkan rasa kesukaan dan keperduliaan pada hal yang dikampanyekan. Tahap akhir adalah tahap Action yaitu meningatkan kembali perubahan perilaku yang tidak hanya dilakukan sekali saja namun berkelanjutan (Yates dalam Nyolinda dan Hartanti, 2016: 19-20).

Adapun retorika visual adalah istilah untuk menggambarkan citra visual melalui disiplin retorika melalui strategi penggunaan simbol dalam gambar. Retorika visual dapat memengaruhi pemikiran dalam membaca makna yang dikomunikasikan dalam visual tersebut (Gregory dalam Wijaya, 2016). Gambar yang bisa dikatakan sebagai retorika visual memiliki tiga karakteristik yaitu gambar harus simbolik, melibatkan intervensi manusia, dan disajikan kepada audien untuk tujuan berkomunikasi dengan audien tersebut. (Foss dalam Wijaya, 2016).

Retorika visual yang dipilih dalam perancangan ini adalah anthropomorpism, yaitu penerapan figural yang non-manusia menjadi karakter yang memiliki bentuk manusia. Anthropomorpism ini juga termasuk dalam tipe retorika personifikasi (Simmons, 2010). Retorika Anthropomorpism digunakan 
untuk menampilkan gaya hidup dari sasaran kampanye melalui produk makanan tersebut. Selain itu digunakan juga metafora untuk menunjukkan kemiripan atau perumpamaan suatu objek dengan penggantinya. Dalam perancangan digunakan untuk menampilkan citra daerah wisata yang ada di Kabupaten Bandung Wilayah Selatan.

Budiman (2011) menjelaskan bahwa leksia yaitu satuan-satuan pembacaan (units of reading) dengan panjang-pendek yang bervariasi. Sepotong bagian teks yang apabila disatukan akan berdampak atau memiliki fungsi yang khas bila dibandingkan dengan potongan-potongan teks lainnya. Leksia biasanya bisa berupa satu-dua patah kata, kadang sekelompok kata, beberapa kalimat, dan kadang sebuah paragraf. Leksia memiliki beberapa kemungkinan makna, tergantung dari konotasi yang bervariasi sesuai dengan penggunaan momen teks (Barthes dalam Budiman, 2011). Leksia dalam perancangan ini termasuk dalam leksia kode simbolik yang akan menjadi sebuah penanda teks sehingga membawa pembacanya memasuki dunia lambang atau tanda-tanda yang memungkinkan adanya pemaknaan yang berkelanjutan (Lantowa, 2017).

Pemasaran media sosial memungkinkan membangun hubungan. Sosial yang lebih personal dan dinamis dibandingkan dengan strategi marketing tradisional. Kegiatan pemasaran media sosial berpusat pada usaha membuat konten-konten yang menarik perhatian dan mendorong pembaca untuk berinteraksi serta membagikannya dalam lingkungan jejaring sosial pertemanan mereka. Pengaruh media sosial berbeda-beda, akan tetapi yang umum terjadi adalah informasi yang berasal dari media sosial akan memberikan pengaruh terhadap keputusan pembelian yang akan diambil konsumen (Nurgiyantoro, 2014).

Jacob Sumardjo, salah seorang budayawan Indonesia menjelaskan bahwa warna juga dipengaruhi oleh perilaku dan lingkungan yang ada disekitar manusia. Dalam masyarakat Sunda warna-warna yang dipakai adalah warna-warna solid 
yang tidak bergradasi atau bukan merupakan warna campuran (Hartanti, 2011). Sumber lain juga mengungkapkan, bahwa Masyarakat Sunda memiliki warna yang dikenal dalam budayanya dengan sebutan tersendiri, sebagaimana diuraikan pada Tabel 1.

Tabel 1. Penerapan anatomi aksara Sunda pada logo kampanye (Sumber: Affendi dalam darmaprawira, 2002)

\begin{tabular}{lll}
\hline Bodas = Putih & Gandaria = Ungu muda & Koneng = Kuning \\
Beureum = Merah & Kasumba = Merah ros & Gedang Asak = Kuning Jingga \\
Bulao = Biru & Kayas = Ros muda & Pulas Haseup = Abu-abı \\
Bulao saheab = Biru muda & Hejo = Hijau & kebiruan \\
Beureum ati = Merah tua & Hejo Lukut = Hijau lumut & Beureum Cabe = Merah tua \\
Beureum cabe = Merah tua & Hejo Paul = Hejo kebiruan & Gading = Kuning Muda \\
& Hideung = Hitam & Paul = Biru Ultramarine \\
\hline
\end{tabular}

\section{METODE PENELITIAN}

Perancangan ini menggabungkan metode analisis kualitatif dan kuantitatif. Metode kualitatif digunakan pada saat observasi yaitu dengan melihat hasil produksi dari produk makanan oleh-oleh di daerah Rancabali, Kabupaten Bandung dan wawancara dengan narasumber Maya Kusuma Dewi, selaku Kepala Seksi Industri Makanan dan Minuman di Dinas Perindustrian Kabupaten Bandung. Dari hasil observasi, ditemukan lebih dari 15 produk olahan makanan yang diproduksi disetiap Kecamatannya. Produksi terbanyak dari beberapa Kecamatan yang ada di Kabupaten Bandung Wilayah Selatan ialah produk olahan stroberi dari Kecamatan Rancabali, opak dari Kecamatan Soreang, bandrek dari Kecamatan Ciwidey, dan kalua jeruk dari Kecamatan Pasir Jambu. Hasil wawancara dengan Ibu Maya Kusuma Dewi, untuk mengetahui produk apa saja yang menjadi ciri khas Kabupaten Bandung khususnya wilayah Selatan serta upaya promosi produk makanan oleh-oleh yang telah dilakukan.

Metode kuantitatif dalam bentuk penyebaran kuesioner kepada 100 responden yang memiliki kisaran umur 17-40 tahun berdomisili di wilayah perkotaan. Kuesioner berisikan pertanyaan yang menggali informasi terhadap 
pengetahuan responden tentang Kabupaten Bandung Wilayah Selatan dan kuliner. Penelitian ini juga didukung dengan studi pustaka dari berbagai sumber yang berhubungan dengan teori kampanye, teori retorika, teori leksia dan cara bertutur kepada remaja hingga dewasa muda.

\section{HASIL DAN DISKUSI}

Berdasarkan pengumpulan data yang telah dilakukan, hasil analisis mengungkapkan bahwa daerah Kabupaten Bandung khususnya Wilayah Selatan memiliki sentra potensi alam yang ada dapat dikembangkan menjadi daya tarik wisata maupun kuliner. Tersedia juga UKM yang mampu mengolah potensi alam tersebut menjadi produk makanan memiliki citarasa khas Bandung Selatan dan dijadikan oleh-oleh. Empat produk makanan oleh-oleh dengan produsen terbanyak adalah opak, bandrek, dodol strawberry dan kalua jeruk. Belum adanya upaya yang dilakukan oleh pemerintah dan swasta dalam bentuk kampanye dengan strategi yang terencana, membuat produk makanan oleh-oleh tersebut masih belum dikenal oleh masayarakat luas.

Kurangnya pengenalan masyarakat menjadi salah satu masalah yang membuat penjualan dari produk makanan oleh-oleh ini belum meluas. Dibanding rasa, responden lebih tertarik dengan kealamian dari bahan dasar produk makanan oleh-oleh khas daerah tertentu, karena menurut penjelasan yang di dapat, suatu daerah biasanya memproduksi makanan khasnya dari keunggulan serta keunikan sumber daya setempat sehinggga makanan tersebut dapat mewakili kekhasan daerah tersebut. Responden kuesioner menyatakan saat ini makanan yang berkesan trendi dianggap lebih menarik dan sesuai dengan gaya hidup mereka (kekinian). Selain itu dari beberapa gaya visual yang kami cantumkan pada kuesioner dalam bentuk perwakilan gambar, responden menyatakan bahwa gaya visual retorika lebih menarik dibandingkan gaya clean design dan vintage. 
Berdasarkan rangkuman hasil analisis diatas, pemecahan masalah yang perlu dilakukan adalah melalui media kampanye. Adapun gaya visual yang akan digunakan dalam perancangan ini adalah retorika Anthropomorpism dan Methapor. Produk makanan tersebut diretorikakan sebagai target market yang sedang berlibur di lokasi Bandung Selatan dengan aktivitas masa kini salah satunya Selfi. Gaya visual tersebut untuk menggambarkan citra visual bahwa produk makanan oleh-oleh khas Bandung Selatan adalah salah satu produk makanan yang alami dan trendi, khususnya bagi remaja dan dewasa muda.

Kampanye ini ditujukan bagi pria dan wanita dengan usia 20-30 tahun yang berdomisili di wilayah perkotaan Jawa Barat yang memiliki ketertarikan terhadap kuliner dan traveling; menyukai hal-hal yang baru; memiliki rasa keingintahuan yang tinggi; berprofesi sebagai pelajar, mahasiswa, karyawan, dengan kelas sosial ekonomi menengah. Dalam perancangan ini dibatasi pada pemilihan empat objek makanan oleh-oleh dengan produsen terbanyak di masing-masing Kecamatan. Makanan tersebut adalah opak dari Kecamatan Soreang, dodol stroberi dari Kecamatan Rancabali, bandrek seduh dari Kecamatan Ciwidey, dan kalua jeruk dari Kecamatan Pasir Jambu.
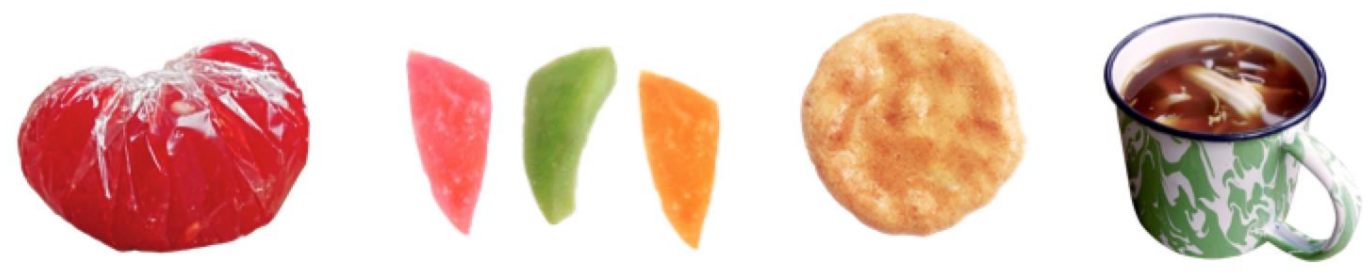

Gambar 1. Foto produk dodol stroberi, kalua jeruk, opak, dan bandrek (Sumber: Birgita, Hartanti dan Tirtaatmadja, 2018)

\section{Tahapan Kampanye}

Konsep komunikasi dalam perancangan kampanye ini adalah ingin menyampaikan kealamian citarasa khas makanan oleh-oleh khas Bandung Selatan 
yang disampaikan dengan cara yang modern dan muda. Pada tahap Awareness, strategi dirancang untuk memperlihatkan kesegaran dan kealamian serta kelokalan dari produk makanan oleh-oleh khas Kabupaten Bandung Selatan dengan gaya visual retorika anthropomorphism dan methapor yang diterapkan pada produk opak, kalua jeruk, manisan strawberry, dan bandrek yang ditampilkan dengan memperlihatkan gaya hidup dari sasaran kampanye yang hendak berwisata ke daerah Kabupaten Bandung wilayah Selatan.

Selanjutnya, tahap Attitude ini dirancang dengan strategi untuk memberikan informasi tentang merek yang menaungi sekaligus proses pembuatan yang menunjukkan kealamian dan kesegaran serta kelokalan produk dengan penggunaan bahasa Sunda sederhana sekaligus memperlihatkan rasa dari masing-masing produk. Terakhir, pada tahap Action ini strategi dirancang agar produsen ingin mencoba ataupun membeli lagi produk-produk makanan oleholeh tersebut dengan cara menampilkan visual yang segar dengan leksia dari masing-masing produk.

Konsep kreatif dalam perancangan kampanye ini dijelaskan sebagai berikut: dalam perancangan kampanye ini menggunakan layout yang sederhana dan ringan. Adapun tipografi yang digunakan dalam perancangan kampanye ini, mengadaptasi anatomi aksara Sunda pada logo kampanye dan menggunakan huruf yang berkesan dinamis, fun yaitu GargleExRg-Bold dan Stereofidelic-Regular, Hobo std medium sebagai teks pendukung.

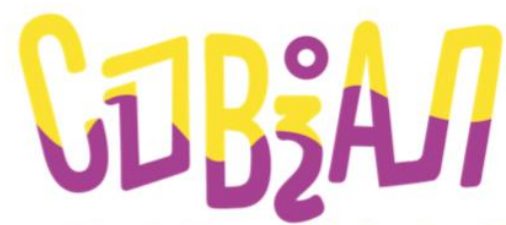

cobi sakali,

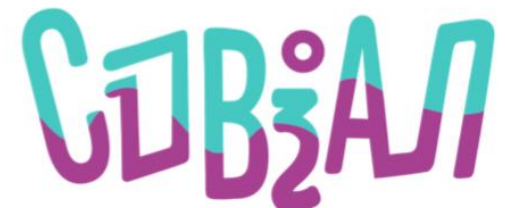

cobi sakali, pasti ketagihan!

Gambar 2. Penerapan anatomi aksara Sunda pada logo kampanye (Sumber: Birgita, Hartanti dan Tirtaatmadja, 2018) 


\title{
Ad Bb Ce Dd Ee Ff Gg Hh li Jj KK LI Mm Nn ๑• Pp Qq
}

\author{
Rr Ss Tt Uu Vv Ww XX Yy Zz
}

1234567890

Gambar 3. Huruf GargleExRg-Bold

(Sumber: www.dafont.com)

AA BB CC DD EE FF GG HH UJ KK LL MM NN OO PP QO

RRSS IT UU W WW XX YY ZZ

\section{0}

Gambar 4. Huruf Stereofidelic-Regular

(Sumber: www.dafont.com)

\section{Aa Bb Cc Dd Ee Ff Gq Hh li Jj Kk LI Mm Nn Oo Pp Qq}

\section{Rr Ss Tt Uu Uv Ww Xx Yy Zz}

\section{0}

Gambar 5. Huruf Stereofidelic-Regular

(Sumber: www.dafont.com)

Warna dalam perancangan kampanye ini diambil dari warna Sunda yang cerah, antara lain hejo paul, koneng, gandaria, hejo, dan paul, untuk memberikan kesan modern, ceria sekaligus tidak menghilangkan kelokalannya. 


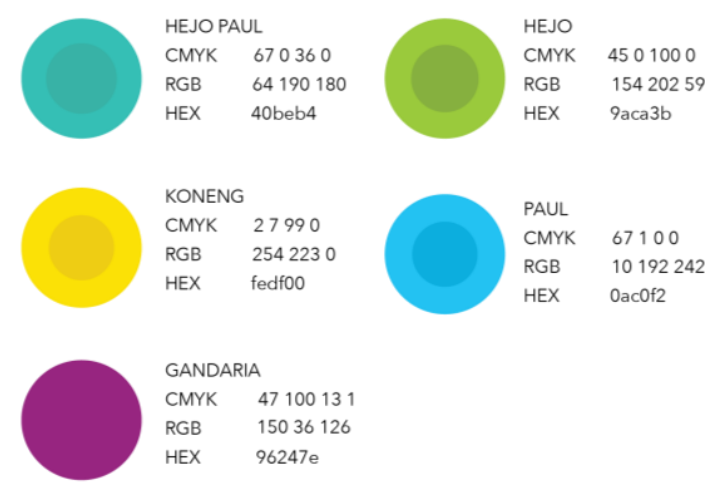

Gambar 6. Warna Sunda yang digunakan dalam perancangan kampanye (Sumber: Birgita, Hartanti dan Tirtaatmadja, 2018)

Gaya visual dalam perancangan kampanye ini memadukan fotografi dari makanan dan vektor. Retorika Anthropomorpism dan Methapor diterapkan pada visualisasi di tahap awareness, dengan subjeknya adalah makanan oleh-oleh tersebut yang melakukan aktivitas seperti manusia. Diperlihatkan kegiatan dan gaya hidup sasaran kampanye saat sedang berwisata, seperti selfie, berkemah dan berendam. Semua kegiatan tersebut dapat dilakukan di tempat wisata yang ada di Kabupaten Bandung Wilayah Selatan, tepatnya di Kecamatan Ciwidey dan Rancabali. Gaya visual pada tahap action dalam perancangan kampanye ini juga didukung dengan teks-teks Leksia kode simbolik berupa suara yang dapat memberi makna yang mampu menunjukan cita rasa khas yang dimiliki oleh masing-masing produk. 


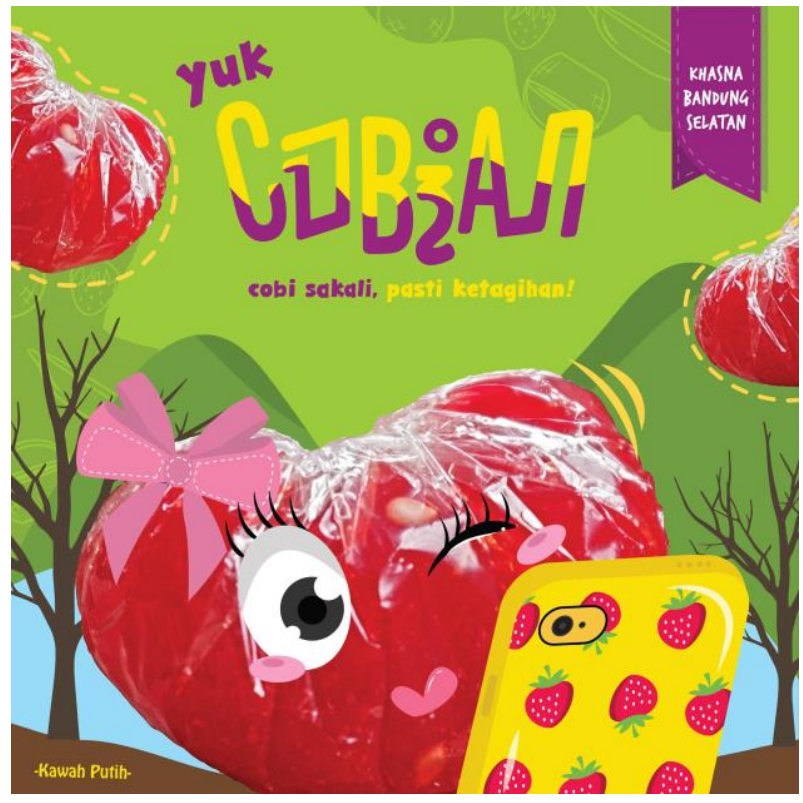

Gambar 7. Awareness yang menggunakan retorika Anthropomorpism pada dodol strawberry yang sedang selfie saat berlibur di kawah putih (Sumber: Birgita, Hartanti dan Tirtaatmadja, 2018)

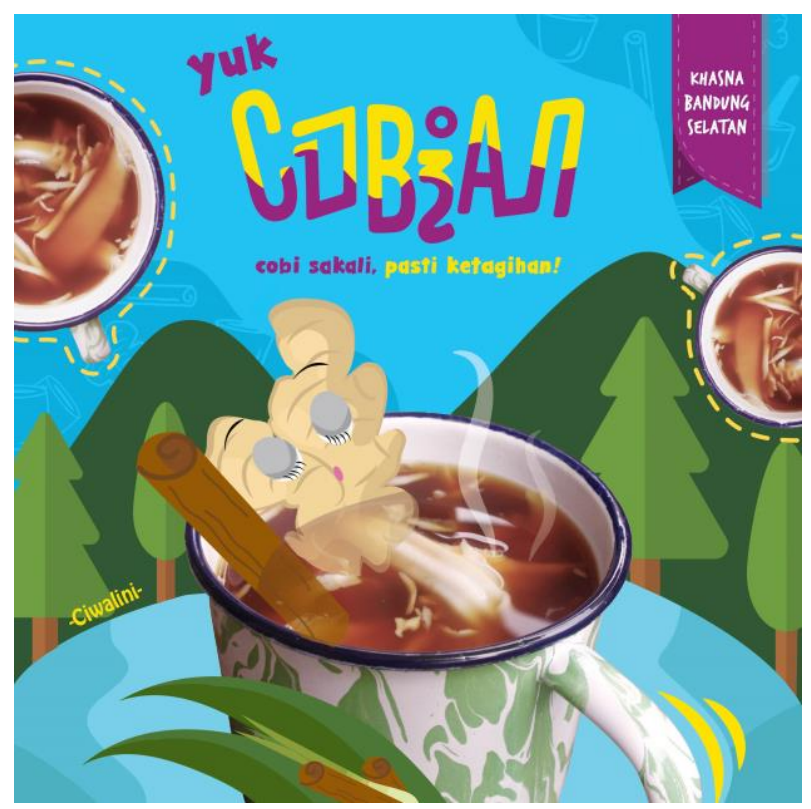

Gambar 8. Awareness yang menggunakan retorika Methapor yang diumpamakan sebagai tempat berendam yang ada di Ciwalini (Sumber: Birgita, Hartanti dan Tirtaatmadja, 2018) 


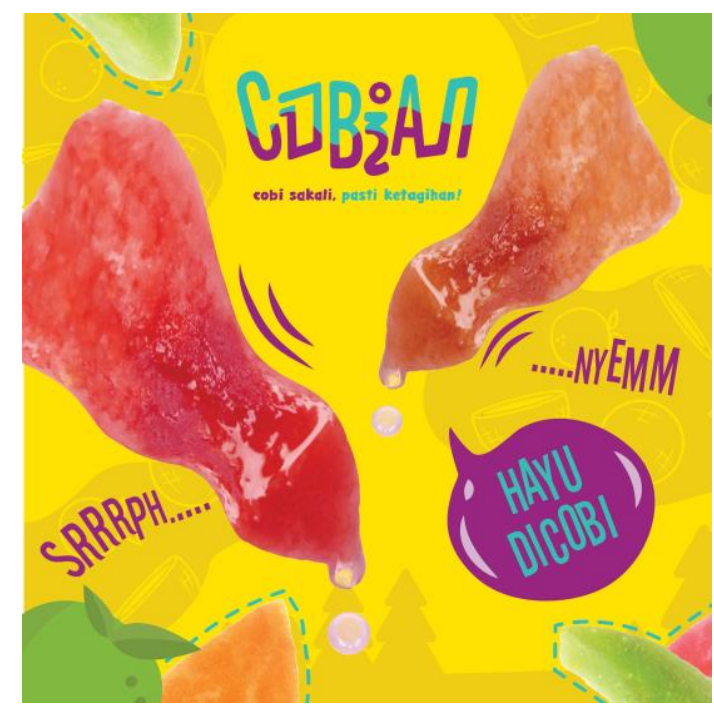

Gambar 9. Action, teks "srrph..., nyemmm" menggunakan Leksia simbolik untuk menunjukkan cita rasa khas dari produk makanan kalua jeruk yang empuk basah. (Sumber: Birgita, Hartanti dan Tirtaatmadja, 2018)

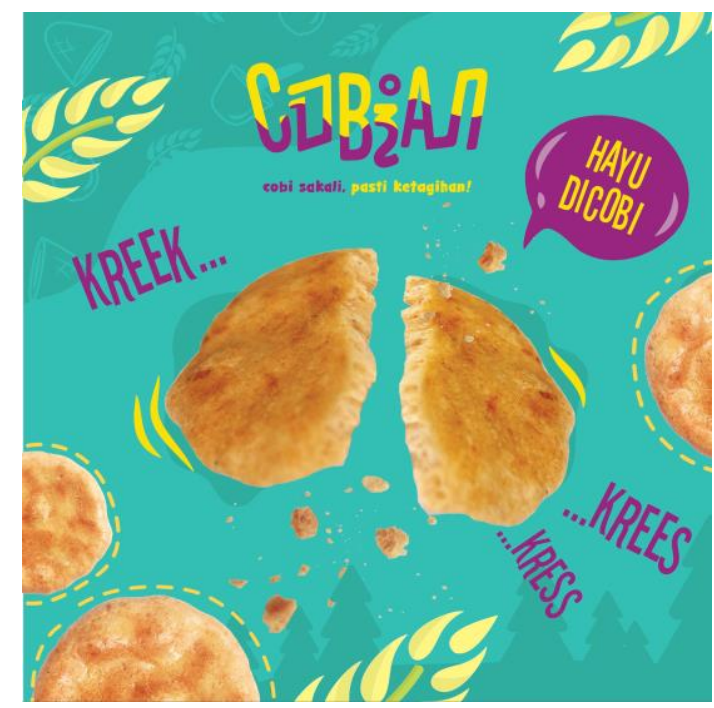

Gambar 10. Action, teks "kreek..., kreess" menggunakan Leksia simbolik untuk menunjukkan cita rasa khas dari produk makanan Opak yang renyah.

(Sumber: Birgita, Hartanti dan Tirtaatmadja, 2018)

Media yang dipilih dalam perancangan ini adalah media yang sesuai dengan karakter dari target marketnya yaitu media yang modern, masa kini, memiliki sebaran yang luas dan juga dipilih media yang low budget dikarenakan 
kampanye ini adalah sebagai upaya memperkenalkan UKM di wilayah Bandung Selatan. Media utama dari perancangan kampanye ini adalah media sosial instagram dan facebook, Sedangkan media pendukungnya ialah web banner, marketplace seperti tokopedia. Media cetak dan media outdoor yaitu poster, umbul-umbul, car ads dan bus ads, $x$ banner dan stopper, disertai juga gimmick yang mendukung dalam kampanye.

Tabel 2. Timeline media kampanye

(Sumber: Birgita, Hartanti dan Tirtaatmadja, 2018)

\begin{tabular}{|c|c|c|c|c|c|c|c|c|}
\hline \multirow{2}{*}{ Media } & \multicolumn{9}{|c|}{ April } & \multicolumn{4}{c|}{ Mei } \\
\hline & w1 & w2 & w3 & w4 & w1 & w2 & w3 & w4 \\
\hline Instagram & & & & & & & & \\
\hline Facebook & & & & & & & & \\
\hline Web banner & & & & & & & & \\
\hline Umbul-umbul & & & & & & & & \\
\hline X Banner & & & & & & & & \\
\hline Bus Ads & & & & & & & & \\
\hline Stoper & & & & & & & & \\
\hline
\end{tabular}

\begin{tabular}{|c|c|c|c|c|c|c|c|c|}
\hline \multirow{2}{*}{ Media } & \multicolumn{5}{|c|}{ Juni } & \multicolumn{4}{c|}{ Jull } \\
\hline & w1 & w2 & w3 & w4 & w1 & w2 & w3 & w4 \\
\hline Instagram & & & & & & & & \\
\hline Facebook & & & & & & & & \\
\hline Web banner & & & & & & & & \\
\hline Umbul-umbul & & & & & & & & \\
\hline X Banner & & & & & & & & \\
\hline Car Adv & & & & & & & & \\
\hline Stoper & & & & & & & & \\
\hline
\end{tabular}

Awareness

Informing

Reminding

Berikut beberapa contoh karya yang diaplikasikan pada media utama:
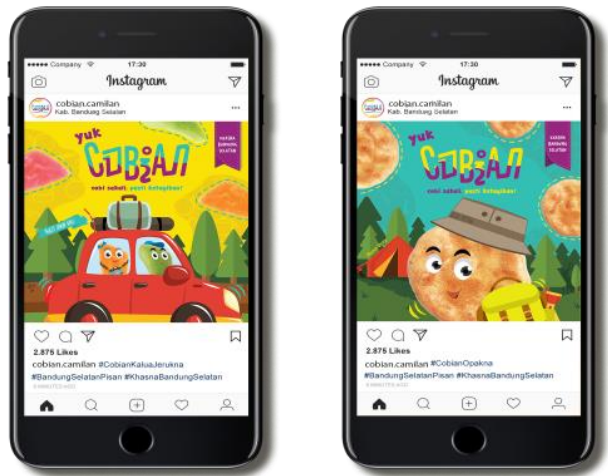

Gambar 11. Awareness pada media instagram (Sumber: Birgita, Hartanti dan Tirtaatmadja, 2018) 


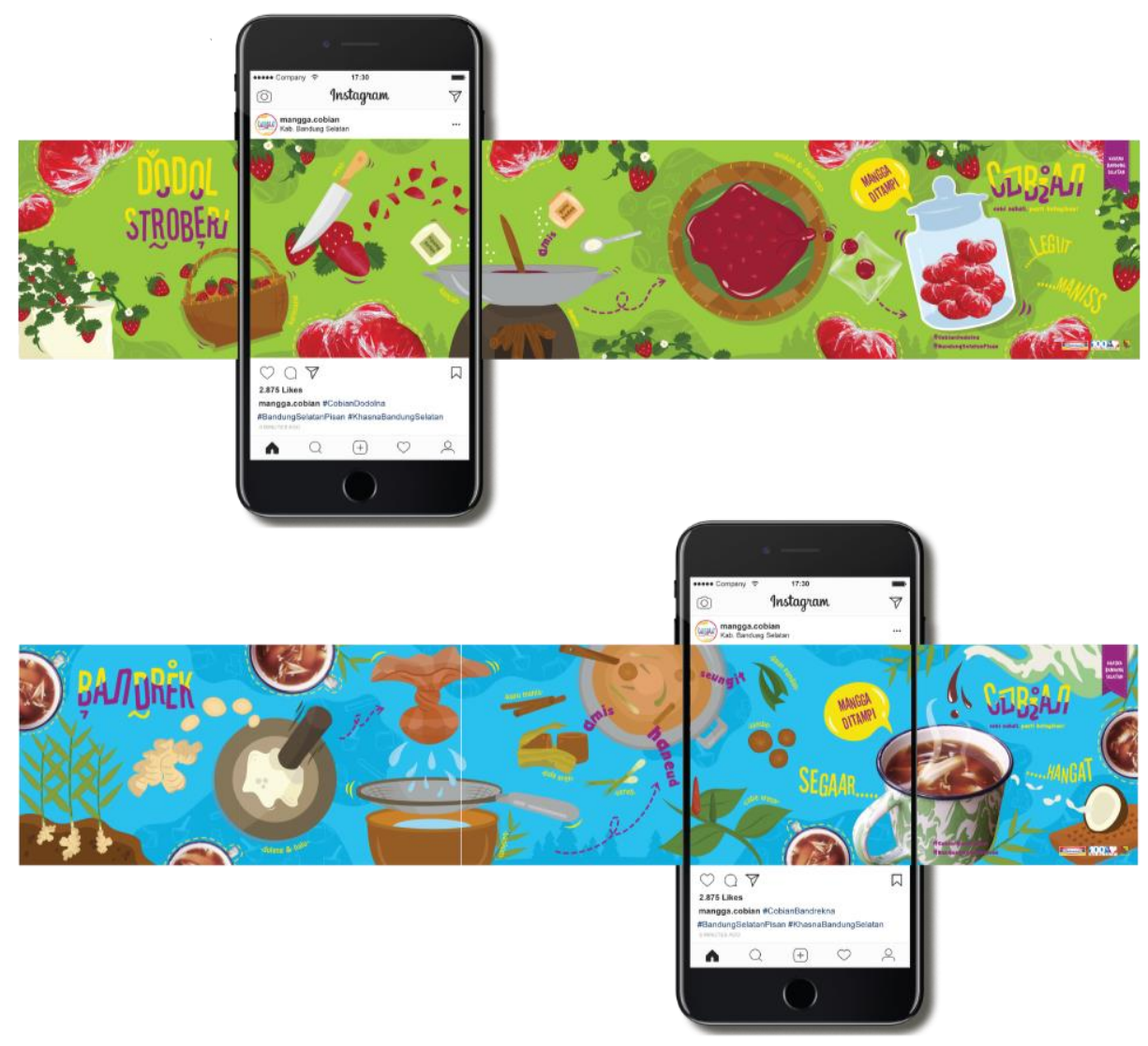

Gambar 12. Attitude pada media Instagram

(Sumber: Birgita, Hartanti dan Tirtaatmadja, 2018)
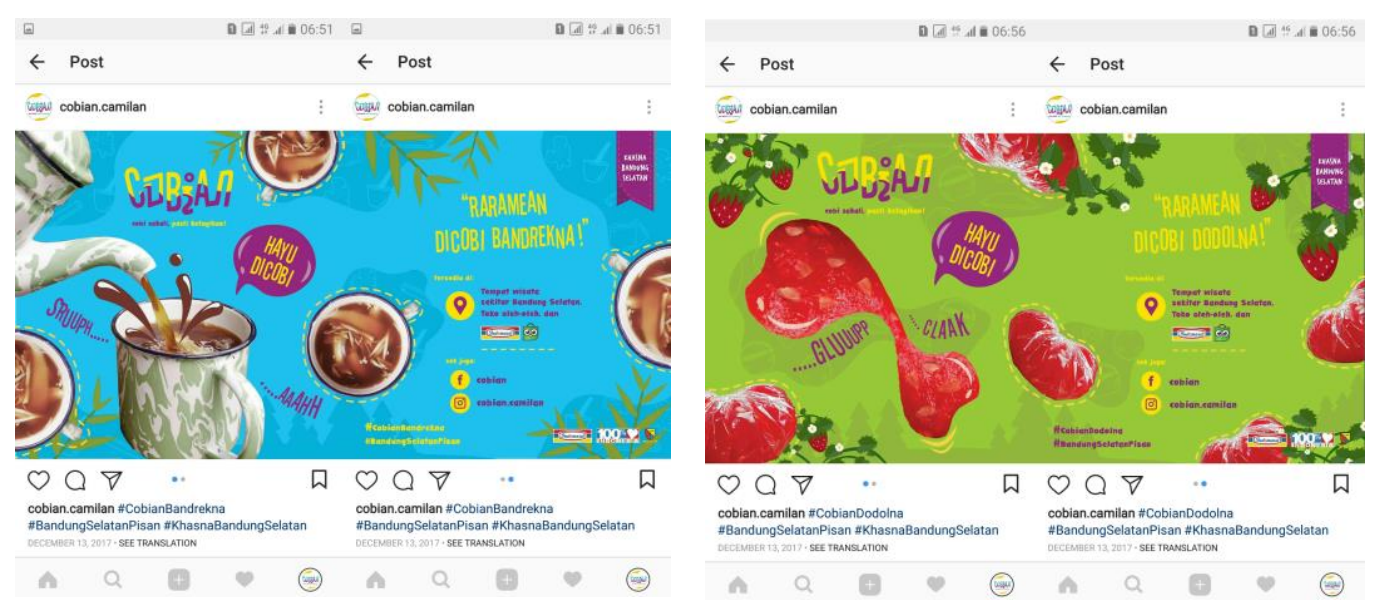

Gambar 13. Action pada media instagram

(Sumber: Birgita, Hartanti dan Tirtaatmadja, 2018) 


\section{KESIMPULAN}

Wadah yang telah disediakan oleh dinas kepada para produsen makanan oleh-oleh di Wilayah Bandung Selatan dirasa belum cukup untuk membuat produknya dikenal secara luas. Upaya pengenalan yang bersifat masal perlu dilakukan. Melalui perancangan kampanye yang didukung dengan strategi media yang tepat dengan visual yang menarik dan komunikatif yang disesuaikan dengan target marketnya diharapkan produk makanan oleh-oleh khas Bandung Selatan yang diolah dari potensi alam sekitar dapat lebih dikenal secara luas.

\section{PERNYATAAN PENGHARGAAN}

Terima kasih kepada Ibu Maya Kusuma Dewi, selaku Kepala Seksi Industri Makanan dan Minuman di Dinas Perindustrian Kabupaten Bandung sebagai narasumber.

\section{DAFTAR PUSTAKA}

Budiman, Kris, 2011. Semiotika Visual. Yogyakarta: Jalasutra

Dewi, Maya Kusuma, 2017. Wawancara untuk keperluan penelitian tugas akhir.

Darmaprawira, S., 2002. Warna: Teori dan Kreativitas Penggunaannya, Penerbit ITB, Bandung.

Hartanti, Monica, 2011. Kajian Emotional Branding dan Budaya etnik Sunda Pada Restoran Tradisional Sunda. Tesis. Bandung: ITB.

Lantowa Jafar, M.M Nila, K. Muh., 2017. Semiotika: Teori, Metode, dan Penerapannya dalam Penelitian Sastra. Sleman: Deepublish.

Nurgiyantoro, Singgih, 2014. Pengaruh Strategi Promosi Melalui Sosial Media Terhadap Keputusan Pembelian GARSKIN yang Dimediasi Word of Mouth 
Marketing. http://eprints.uny.ac.id/16797/1/SKRIPSI.pdf. Diakses pada 3 November 2017.

Nyolinda, V.A. dan Hartanti, M., 2016. Campaign to Introduce Children Yoga to the Mothers in Bandung City, Journal of VCD Vol.1 No.1, 19-20. https://journal.uc.ac.id/index.php/VCD/issue/view/35 diakses pada 19 Maret 2018

Simmons, Eugene Bradley, 2010. Humanizing the Humvee: Personi cation techniques and visual rhetoric as used in a U.S. Army technical comic book.https://lib.dr.iastate.edu/cgi/viewcontent.cgi?article=2516\&context =etd. Diakses pada 19 Maret 2018

Venus, Antar, 2004. Manajemen Kampanye: Panduan Teoritis Dan Praktis Dalam Mengefektifkan Kampanye Komunikasi. Simbiosa Rekatama Media

Wijaya, Bergas Adhi, 2016. Analisis Retorika Visual Pada Iklan A Mild Versi Manimal.https://www.academia.edu/31646760/Analisis_Reto rika_Visual_Pada_Iklan_A_Mild_Versi_Manimal_VISUAL_RHETORIC_ANA LYSIS_ON_A_MILD_MANIMAL_VERSION_ADVERTISEMENT_Diakses pada 19 Maret 2018 